Revue d'histoire de l'enfance « irrégulière »

Le Temps de l'histoire

2 | 1999

Cent ans de répressions des violences à enfants

\title{
La justice et les violences parentales à la veille de la loi de 1898
}

Jean-Jacques Yvorel

\section{(2) OpenEdition \\ 12 Journals}

Édition électronique

URL : http://journals.openedition.org/rhei/30

DOI : $10.4000 /$ rhei.30

ISBN : 978-2-7535-1639-7

ISSN : $1777-540 \mathrm{X}$

Éditeur

Presses universitaires de Rennes

Édition imprimée

Date de publication : 15 novembre 1999

Pagination : 15-45

ISSN : 1287-2431

Référence électronique

Jean-Jacques Yvorel, « La justice et les violences parentales à la veille de la loi de 1898 », Revue

d'histoire de l'enfance « irrégulière » [En ligne], 2 | 1999, mis en ligne le 08 juin 2007, consulté le 03

décembre 2020. URL : http://journals.openedition.org/rhei/30 ; DOI : https://doi.org/10.4000/rhei.30 


\section{La justice et les violences parentales à la veille de la loi de 1898}

\author{
Jean-Jacques \\ Yvorel $^{(1)}$ \\ avec la \\ collaboration de \\ Gérard Rosset ${ }^{(2)}$ \\ et l'aide \\ d'Élise Yvorel ${ }^{(3)}$
}

(1) Historien, chargé d'études au CNFE-PJJ.

(2) Statisticien,

CNRS/2RJ, qui a assuré le traitement des données numériques.

(3) Qui s'est chargée du codage des données.

(4) Déposé le

17 décembre 1891, ce projet de loi vise à punir les bourreaux d'enfants des mêmes peines que celles prévues pour les violences commises par des enfants contre leurs ascendants, qui aboutissaient à un renvoi en Cour d'assises. Cf. Pierre LASCOUMES, Pierrette PONCELA, Pierre LENOEL, Les Grandes phases d'incrimination. Les mouvements de la législation pénale, 1815 1940, Paris, 1992, p.169. 
(5) A.N. BB-18-1871, Circulaire du directeur des affaires criminelles et des grâces

(6) Bien que la qualification exacte ne soit pas indiquée, nous pouvons supposer que les articles 309 et suivants sont le plus souvent invoqués. Certaines affaires cependant relèvent des articles 319 et 320 qui traitent des "Homicides, blessures et coups involontaires".

(7) Il s'agit d'affaires jugées l'une à Rennes, l'autre à Chambéry.

(8) A.N., BB-18-1871, lettre d'accompagnement du procureur général de Paris.

(9) Nous renvoyons aux très nombreux articles et ouvrages sur l'usage des statistiques judiciaires.

(10) Nous ignorons le sexe d'une seule personne.

(11) A.N., BB-181871, Cour de Bordeaux, la Seine et les employés de mon parquet à ne mentionner que la dernière année (1891) pour le tribunal de la Seine et les deux dernières années (1890-1891) pour la cour de Paris ". ${ }^{(8)}$ Malgré ses imperfections, cet échantillon permet de mieux connaître les auteurs et les victimes des violences à enfants ainsi que les formes prises par ces sévices, du moins pour les affaires qui parviennent devant les juridictions. Ces dernières reflètent davantage, nous le savons, les mouvements d'opinion et les pratiques des tribunaux que l'évolution des délits à proprement parler ${ }^{(9)}:$ l'enquête de 1891 nous éclaire avant tout sur les politiques judiciaires et l'essor du "sentiment de l'enfance".

\section{I) MALTRAITANCE À ENFANTS : ESSAI DE DESCRIPTION}

\section{A) LES AUTEURS DE VIOLENCES \\ $\left.1^{\circ}\right)$ Sexe, âge et profession}

Les hommes sont un peu plus violents que les femmes, mais la différence n'est pas très significative. Sur 733 personnes mises en cause, nous trouvons 375 hommes $(51,23 \%)$ et 357 femmes $(48,77 \%) .{ }^{(10)}$ Cette faible différence montre bien que l'usage de la violence n'est pas, du moins dans le cadre intrafamilial, l'apanage des hommes.

Nous ne connaissons l'âge que de 393 auteurs sur un total de 733. Le seul jeune tortionnaire est un garçon de 10 ans qui "collabore" avec son père pour supplicier sa jeune sœur..$^{(1)}$

Tableau $n^{\circ} 1:$ Âges des auteurs

\begin{tabular}{c|c|c|c|c|c|c|c}
$\begin{array}{c}<\text { de } \\
\text { ans }\end{array}$ & $\begin{array}{c}\text { de } 25 \\
\text { à } 29 \\
\text { ans }\end{array}$ & $\begin{array}{c}\text { de } 30 \\
\text { à } 34 \\
\text { ans }\end{array}$ & $\begin{array}{c}\text { de } 35 \\
\text { à } 39 \\
\text { ans }\end{array}$ & $\begin{array}{c}\text { de } 40 \\
\text { à } 44 \\
\text { ans }\end{array}$ & $\begin{array}{c}\text { de } 45 \\
\text { à } 49 \\
\text { ans }\end{array}$ & $\begin{array}{c}>\text { de } \\
50 \\
\text { ans }\end{array}$ & Total \\
\hline 25 & 54 & 87 & 72 & 70 & 43 & 42 & 393
\end{tabular}

Effectifs cumulés : 393 sur 733 - Moyenne : 37,3 ans

Le croisement de la variable âge et de la variable sexe fait ressortir un décalage significatif. Les femmes sont en moyenne plus jeunes que les 
hommes, ${ }^{(12)}$ ce qui était prévisible, mais l'écart est très supérieur à ce que laissait prévoir un indicateur comme l'âge au mariage. ${ }^{(13)}$ La jeune mère estelle plus facilement martyrisante que la femme plus mûre? Nous ne pouvons que poser la question.

\section{Répartition des hommes et des femmes selon les tranches d'âge}

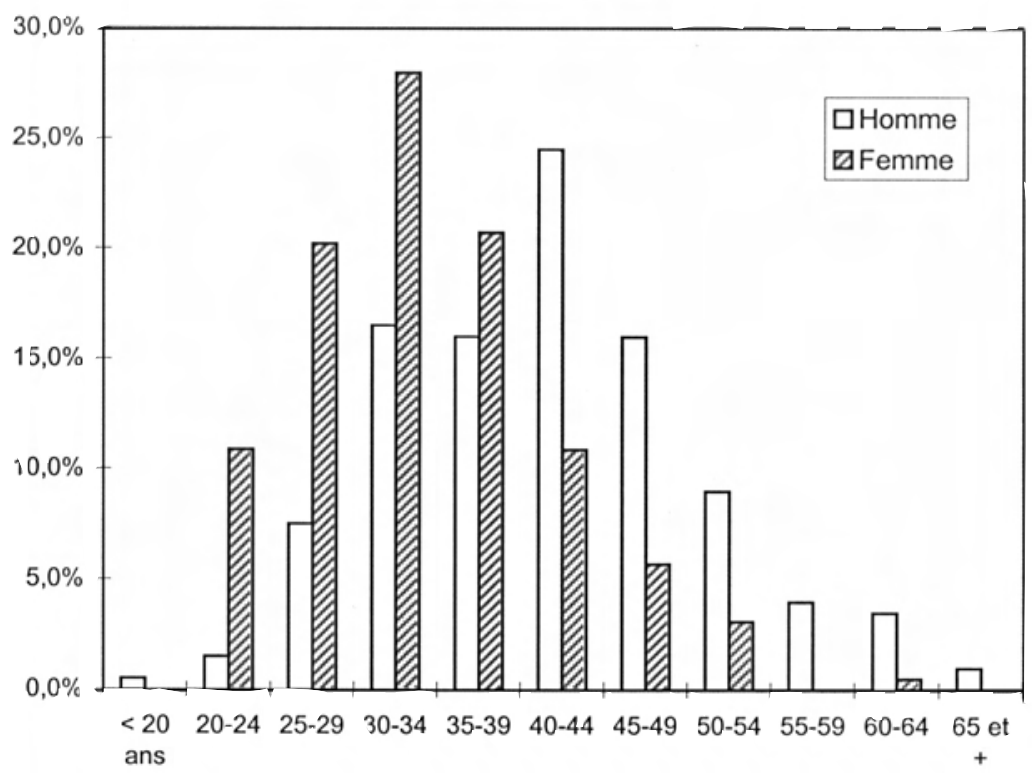

Nous avons une indication de la profession, bon indicateur de l'appartenance sociale, pour 403 inculpés. Outre le fort taux d'indétermination, l'imprécision des catégories utilisées par les magistrats ou les greffiers ne permet pas de comparaison avec la population générale. Si, dans leur immense majorité, les auteurs de violences semblent appartenir à des milieux modestes, ${ }^{(14)}$ nous trouvons quand même un dentiste, ${ }^{(15)}$ un opticien ${ }^{(1)}$ quelques agriculteurs et fermiers donnés comme aisés, et un fils de bonne famille morphinomane dont la violence préoccupe personnellement le Garde des sceaux. ${ }^{(17)}$ La maltraitance "bourgeoise" ne se rencontre pas que dans la littérature... ${ }^{(18)}$
Tribunal d'Angoulême, jugement du

27/12/1988. Le garçon est envoyé en maison de correction pour 5 ans... et le père en prison pour 3 mois. Nous avons aussi le cas d'un garçon de 13 ans qui participe aux violences exercées par sa mère sur son frère, mais il n'est pas inculpé.

(12) Les femmes auteurs ont en moyenne 33,7 ans (médiane 32,21 ans), les hommes 41 ans (médiane 40 ans).

(13) Les hommes se marient à 27 ans, les femmes autour de 24 ans.

(14) On relève notamment 67 ouvriers, 94 journaliers, 18 manœuvriers.

(15) A.N., BB-181871, Cour de Rouen, Tribunal d'Evreux, jugement du 21/12/1890. Par la suite, pour les références issues de BB-18-1871, nous indiquerons simplement 
la cour, le tribunal, la date de l'affaire et le résultat d'un éventuel appel.

(16) Cour d'Amiens, Tribunal de Clermont, 29/10/1890.

(17) Cette affaire est classée séparément dans BB-18-1871.

La demande d'information est adressée directement par le Garde au procureur de la Seine et mentionne le nom de l'inculpé, qui sera jugé irresponsable suite aux expertises des docteurs Motet et Garnier.

(18) Nous pensons entre autres à L'Enfant de Jules Vallès, et notamment au chapitre intitulé "Louisette", mais aussi aux livres de la

Comtesse de Ségur.

(19) Nous ignorons le statut matrimonial d'un couple. Nous avons également un couple père/fils aîné déjà évoqué et un couple mère/frère (oncle de l'enfant).

\section{$2^{\circ}$ ) Le lien de parenté adulte(s)/enfant(s)}

Les violences sont le plus souvent le fait d'un seul adulte de la cellule familiale : 533 auteurs sur 733 agissent seuls. Dans 100 affaires, c'est un couple qui se retrouve devant le juge. Il peut s'agir de couples légitimes en premières noces (60 cas), de couples légitimes en secondes noces $\left(21\right.$ cas) ou de concubins (16 cas). ${ }^{(19)}$

Parmi les "tourmenteurs", nous trouvons quelques portraits attendus, comme celui de la marâtre (50 cas) ou du beau-père (22 cas). Cependant, dans les cas de familles recomposées, pour user d'une expression actuelle, il arrive que le géniteur (ou la génitrice) soit seul à persécuter l'enfant, voire que le nouveau conjoint joue un rôle protecteur. Ainsi, Louis Émile C. qui avait légitimé la fille de sa femme, Marie G., se montre "bon et affectueux pour l'enfant ", alors que la mère, déjà condamnée en 1883 à trois mois de prison pour mauvais traitements, continue ses exactions. "Son mari dut la dénoncer lui-même à la gendarmerie. Elle avait frappé sans motif sa fille âgée de 8 ans, qui avait les deux yeux tuméfiés [...] et un pouce luxé ". ${ }^{(20)}$

Les nourrices, si fortement décriées dans les écrits médicaux et philanthropiques, justifient rarement leur mauvaise réputation, ${ }^{(21)}$ mais elles ont pu être laissées en dehors de l'enquête car elles ne peuvent logiquement pas être assimilées à des ascendants. Le tuteur qui dépossède l'enfant confié à sa garde et le martyrise n'est pas une simple figure de la littérature populaire : nos archives nous en fournissent un exemple. Le tribunal de Lyon condamne à 8 mois de prison un cultivateur de Moingt qui " réalisa les biens de sa pupille dont il s'appropria le produit ", puis " accabla cette enfant [âgée de 4 ans] des plus barbares traitements ", allant jusqu'à la "frapper avec un pique-feu préalablement rougi au feu ". ${ }^{(2)}$

Nous trouvons aussi quelques portraits inattendus, comme ces 5 grands-mères et ces 5 grands-pères qui, façon particulière de cultiver l'art d'être grands-parents, martyrisent leurs petits enfants.

Ces cas particuliers ne doivent pas masquer l'essentiel, à savoir que pour la plupart les enfants sont victimes de leur père ou de leur mère légitimes ou naturels. Parmi les 375 hommes inculpés, nous trouvons 323 pères légitimes $(86,1 \%)$ et 5 pères naturels. Sur les 357 femmes 
mises en cause, nous comptons 241 mères légitimes $(67,5 \%)$ et 46 mères naturelles $(12,9 \%)$.

(20) Cour de Nancy, Tribunal de Bar-le-Duc, 28/06/1887.

(21) Cour de Lyon, Tribunal de Lyon, 23/10/1890.

(22) Cour de Lyon,

Tribunal de Lyon, 27/10/1891, jugement confirmé en appel.

Quand un seul adulte est actif dans le processus de maltraitance, le silence de l'autre est, à quelques exceptions près, la règle. Nous pouvons cependant relever deux attitudes : soit le conjoint élabore une stratégie de protection de l'enfant, soit il semble indifférent au sort qui lui est fait. La première est illustrée par le mari de Catherine R., ménagère à Lyon, qui martyrise l'un de ses enfants, un petit garçon âgé de 10 ans. Pour protéger son fils, le père met l'enfant en pension mais, pendant les congés, " elle le frappait avec un tisonnier ou avec une corde ". Une affaire jugée à Nevers pourrait rendre compte de la seconde; on y voit une femme qui, 
(23) Cour d'Amiens, Tribunal de Clermont, $27 / 11 / 1890$ et 09/04/1891.

(24) Cour de Caen, Tribunal d'Alençon, 18/03/1890.

(25) Cour de Lyon, Tribunal de Roanne, 12/07/1889. "pour la moindre chose ", frappait ses enfants jusqu'au sang, pendant que le père laissait faire et "fumait tranquillement sa cigarette». En fait, le plus souvent, l'indifférence est faite plus de lâcheté que de cynisme, comme le note le procureur de Clermont qui commente deux affaires :

- « Le sieur R., qui n’ignorait pas ces violences, les tolérait pour ne pas mécontenter sa femme».

- «Le Sieur Y., qui n'osait pas intervenir, a soutenu qu'il ignorait ces brutalités ${ }^{(23)}$

\section{$\left.3^{\circ}\right)$ Monoparentalité et maladie mentale}

N'oublions pas enfin que le parent "martyriseur" peut être un parent isolé; la famille monoparentale n'est pas une "invention " du second XXe siècle : 14 hommes (10 veufs et 4 séparés/divorcés) et 48 femmes (25 veuves, 21 "filles" et 2 séparées/divorcées) sont explicitement présentés comme élevant seuls leur(s) enfant(s).

Les juges demandent certaines fois l'éclairage d'un expert, non d'un médecin "ordinaire" pour détecter les traces de mauvais traitements, mais d'un aliéniste pour évaluer la santé mentale du prévenu. Le tribunal d'Alençon relaxe une mère dont la violence est manifeste : "Traduite devant le tribunal correctionnel, la femme P. fut acquittée. Le tribunal, tout en admettant que la prévenue avait porté des coups à sa fille Gilberte, estima que l'intention coupable n'était pas suffisamment établie à raison surtout de l'état d'bystérie qui pouvait, dans certains moments, annuler chez elle la responsabilité ". ${ }^{(24)}$

Geneviève B. a tenté de se suicider avec ses 4 enfants. Les experts ont des avis contradictoires; ils ne s'accordent pas sur la responsabilité ni sur les risques de réitération par cette aubergiste de 31 ans. Le tribunal de Roanne l'acquitte. Deux ans plus tard, au cours d'une nouvelle tentative, les quatre enfants trouveront la mort. La mère survivra et sera internée. ${ }^{(25)}$

\section{B) LES VICTIMES}

\section{$\left.1^{\circ}\right)$ Sexe, âges}

Les filles sont plus souvent victimes que les garçons de mauvais traitements. L'écart n'est pas considérable mais déjà significatif; sur 679 enfants dont nous connaissons le sexe, nous avons 362 filles (53,31 \%) 
et 317 garçons (46,69\%). Les enfants ont entre quelques jours et 20 ans.

Tableau $n^{\circ} 3$ : âges des enfants

\begin{tabular}{c|c|c|c|c|c|c} 
& $\begin{array}{c}\text { de 0 } \\
\text { à 2 } \\
\text { ans }\end{array}$ & $\begin{array}{c}\text { de 3 } \\
\text { à } \\
\text { ans }\end{array}$ & $\begin{array}{c}\text { de 7 } \\
\text { à 12 } \\
\text { ans }\end{array}$ & $\begin{array}{c}\text { de 13 } 13 \\
\text { à } \\
\text { ans }\end{array}$ & $\begin{array}{c}19 \\
\text { et 20 } \\
\text { ans }\end{array}$ & Total \\
\hline effectifs & 76 & 180 & 312 & 177 & 15 & 760 \\
$\%$ & 10,0 & 23,7 & 41,0 & 23,3 & 2,0 & 100
\end{tabular}

Effectifs cumulés : 760 sur 805

Les filles sont sensiblement plus âgées que les garçons, avec un âge moyen de 9 ans et 11 mois contre 8 ans et 6 mois.

\section{Répartition des garçons et filles selon les tranches d'äge}

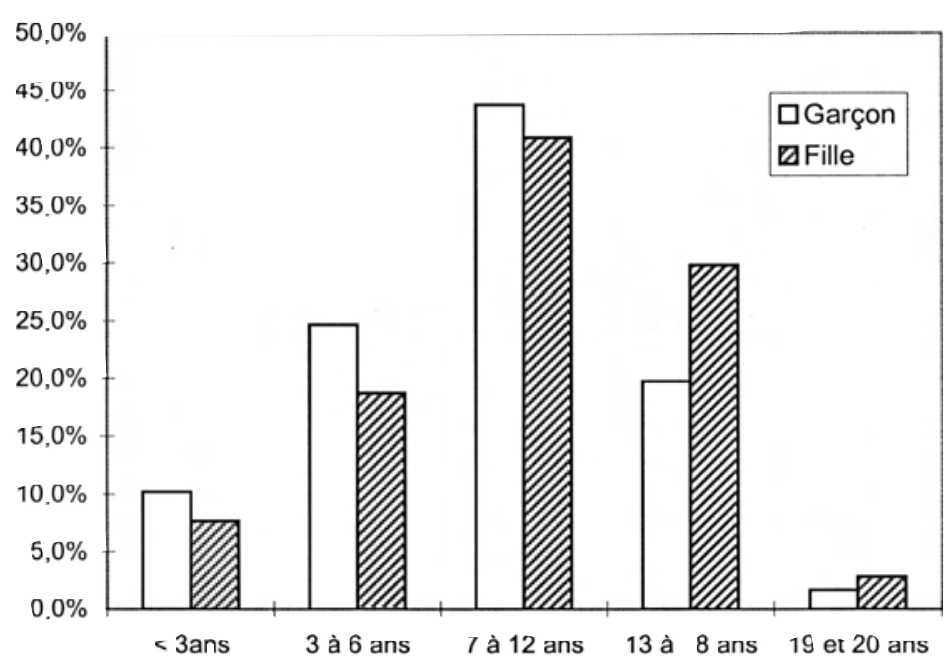


(26) Cour de Paris,

Tribunal de Reims, 19/04/1891.

(27) Cour d'Agen, Tribunal de Lectoure, 10/10/1889.

(28) Cour d'Agen, Tribunal de Cahors, $12 / 10 / 1889$.

(29) Cour d'Aix, Tribunal de Nice, 1891. Le procureur de Nice n'indique que l'année.

(30) Cour d'Amiens, Tribunal de Beauvais, 16/07/1890.

\section{$2^{\circ}$ ) Les "enfants symptômes"}

Si l'enfant n'est pas unique, les violences pourront être généralisées c'est-à-dire concerner l'ensemble de la fratrie et même inclure l'épouse - ou centrées sur un seul enfant. Nous avons repéré 92 affaires qui relèvent de cette problématique de "l'enfant symptôme", pour user d'une expression de nos modernes psychologues. Ils occupent apparemment une place particulière dans l'histoire de la famille : fruit d'un précédent mariage (enfant légitime) ou d'une liaison officieuse (enfant naturel), par exemple. Statistiquement, le phénomène se traduit par une légère sur-représentation des enfants naturels, des enfants légitimés ou des beaux-fils et belles-filles dans ce sous-ensemble. C'est ainsi que les époux Angèle et Paul C. éduquent sans violence les trois enfants issus de leur union, mais frappent, notamment à coups de tisonnier, le petit Philippe C., fruit d'un précédent mariage de monsieur. ${ }^{(26)}$

Dans les familles conjugales "classiques", la victime est souvent un dernier enfant non voulu. G., par exemple, éprouve " une telle aversion pour son jeune enfant [dernier né], Ludovic, âgé de 30 mois, qu'elle le maltraitait à tout propos, le lavait à l'eau froide, lui mettait ses excréments dans la bouche et le battait soit avec la main, soit avec une gaule, soit avec un manche à balai. Il résultait aussi du P.V. que la femme G. privait son fils de manger et s'opposait à ce que ses voisins lui donnent du pain ". (27) Quant au nouveau-né de Jean-Baptiste C., il est trouvé "la verge liée avec force par un fil, de façon à l'empêcher d'uriner ". Ce père de trois enfants, dont le cadet a 15 ans, avait déclaré devant ses voisins : "Plaise à Dieu qu'il nous le prenne; nous allions bien, cet enfant nous dérange tous ». Pour avoir ainsi tenté de se substituer à la "divine providence", le tribunal de Cahors le condamne à trois mois de prison. ${ }^{(28)}$

Les magistrats soulignent parfois que la victime a passé sa prime enfance hors de sa famille. Joséphine est élevée jusqu'à l'âge de 14 ans à l'orphelinat de Monaco. Quand son père la récupère, il tente d'abuser d'elle avant de la frapper, car elle lui résiste. Il sera déchu de ses droits et condamné à 3 mois de prison. ${ }^{(29)}$ Marie, 15 ans, est maltraitée par sa mère depuis qu'elle a quitté l'asile des sourds-muets de Laon. ${ }^{\left({ }^{30)}\right.}$ Jeanne, enfant naturelle, a 7 ans quand elle quitte l'hospice où Marie T., sa 
mère, l'avait placée. Elle rejoint le couple nouvellement et légalement formé par Marie et Alfred B. "L'enfant fut aussitôt l'objet de leur part de mauvais traitements; elle était battue fréquemment; on ne lui donnait pas à manger l'obligeant à mendier pour se nourrir; la nuit, on la couchait nue sur la paille, les mains liées derrière le dos, en la couvrant seulement d'un sac ». ${ }^{(31)}$

\section{C) LES FORMES DE VIOLENCE}

Dans les affaires qui arrivent devant les tribunaux, nous trouvons essentiellement des coups. Les cas où le procureur peut écrire, comme dans l'affaire L., habitant de Lus-la-Croix-Haute qui a frappé assez violemment son fils de 18 ans, "Cette scène a été accidentelle et L. ne maltraitait pas habituellement ses enfants " ${ }^{(32)}$ ne constituent pas une catégorie dominante. Les tribunaux jugent 66 auteurs auxquels ne peuvent être reprochés que des coups apparemment occasionnels.

Généralement les résumés parlent de maltraitance quotidienne, de coups fréquents, de brutalités journalières. ${ }^{(33)}$ Les rapports mentionnent souvent l'usage d'objets contondants tels que des manches de balais, des bâtons, des ceintures, des tisonniers, des pincettes à bûches. Des instruments de ménage comme des casseroles, des marmites, des poêles ou des outils comme les pelles, des fourches et autres instruments aratoires sont également mentionnés. Nous trouvons même un marteau et un fusil de chasse. Quand aucun objet n'est utilisé, on parle de coups de poing, de coups de pied, de projections au sol, de piétinements. Nous rencontrons aussi plusieurs cas d'enfants jetés dans des mares, des fossés ou des rivières.

La chronique judiciaire nous rapporte notamment les méfaits de pères de famille qui s'adonnent parfois à l'ivrognerie ${ }^{(34)}$ et distribuent assez équitablement les coups entre femme et enfants. Par exemple, le tribunal d'Amiens condamne, en 1891, à 4 mois de prison, un plafonneur de 55 ans qui "dissipait son argent au cabaret et maltraitait sa femme et ses deux filles ". Parfois, l'épouse est la seule victime originelle de l'ébriété du chef de famille. L'enfant, souvent dans ce cas un adolescent, n'apparaît alors dans la procédure que parce qu'il cherche à s'interposer entre ses parents et "hérite" de la colère paternelle. Dans ces deux cas de figure,
(31) Cour d'Amiens,

Tribunal de La Cour, 04/05/1888.

(32) Cour de Grenoble, Tribunal de Die, 28/10/1891.

(33) L'item "coups fréquents" apparaît 548 fois.

(34) Sur 70 affaires où la femme est aussi victime de violences, l'ivresse est mentionnée 29 fois et, globalement, l'intempérance est signalée dans 125 affaires. 
(35) Cour de Rennes, Tribunal de Vannes, 01/02/1888. la mère est souvent à l'origine de la saisine de la justice; saisine tardive qui arrive après des mois, voire des années de souffrance. Notons que le tyran domestique peut aussi être une femme (2 cas), comme Marie Mathurine S., cultivatrice à Colso, qui frappe et terrorise ses deux bellesfilles âgées de 9 et 14 ans et son mari infirme. ${ }^{(35)}$

Les tribunaux ont également à connaître des cas d'absence de soins, de privation de nourriture, qui vont parfois jusqu'à entraîner la mort. Le délaissement constitue à lui seul le motif de 25 inculpations, mais nous le trouvons dans 210 autres affaires où il accompagne d'autres sévices, le plus souvent des coups.

L'exploitation économique n'est pas absente du tableau de la misère enfantine. Cosette est un personnage de fiction, une représentation, mais pas un mythe : les tâches ménagères ou productives qui excèdent les forces de l'enfant et dont l'exécution s'accompagne de coups et de brimades ne sont pas rares. Fréquente aussi, l'utilisation des enfants à la mendicité : l'insuffisance de la recette se traduit par une correction.

Les attentats à la pudeur et les problèmes d'inceste sont rares dans notre échantillon (6 cas), mais il faut noter que l'enquête porte sur la violence "classique". Les délits et crimes sexuels apparaissent donc marginalement, quand la résistance de la jeune fille a provoqué des coups. Le tribunal de Lille traite, par exemple, deux dossiers à connotations sexuelles. Le premier concerne un menuisier de 47 ans et sa fille de 16 ans : "M. portait neuf coups de tranchet à sa fille Barbe; il n'a pas été possible d'établir d'une façon positive quel a été le mobile de l'attentat commis par M. sur sa fille, mais tout fait supposer qu'il a agi sur le refus de celle-ci de se livrer à lui ». Dans la seconde, un mouleur de 45 ans, qui tente de violer sa fille de 14 ans, "fut surpris par sa femme qui porta plainte. Le soir même il frappa sa femme et sa fille ".

Enfin, au sommet de la hiérarchie des violences, les juges sont confrontés à des faits qui seraient aujourd'hui qualifiés "d'actes de barbarie" : 143 inculpés comparaissent dans des affaires où les coups, les privations de nourriture et de soins sont associés à de véritables supplices. Greniers, caves, porcherie, écurie fonctionnent alors comme des lieux de relégation... et comme chambre de torture. 


\section{CONCLUSION}

Les situations entrevues dans ces 633 affaires ne different guère phénoménologiquement de celles que nous pouvons connaître aujourd'hui. Le père dont la violence est proportionnelle à la disqualification, l'enfant initialement placé dont le retour tourne au drame sont le lot quotidien des travailleurs sociaux. Un enfant, issu d'une première union, rejeté au fond d'un placard, a fait la une de nos journaux. L'alcool, la drogue et la maladie mentale jouent encore maintenant un rôle dans la violence intrafamiliale. Les difficultés matérielles, la misère aggravent les situations et exacerbent une violence sûrement latente. La monoparentalité isole et donc fragilise toujours les individus. Bref, les formes de la violence, les caractéristiques des auteurs, celles des victimes, les causes même du mal ne nous semblent pas avoir connu de grands bouleversements. Qu'en est-il de l'attitude de la justice et de la société civile?

\section{II) LATTITUDE DE LA JUSTICE ET DE LA SOCIÉTÉ CIVILE}

Si nous nous en tenons aux données statistiques brutes, les décisions de justice semblent d'une grande uniformité et la peine de prison ferme la réponse habituelle des tribunaux. Elle est prononcée comme sanction à l'égard de 596 prévenus sur un total de $733,{ }^{(36)}$ soit dans $81,5 \%$ des cas. Il s'agit le plus souvent d'une peine inférieure à 6 mois $(430$ cas, soit $58,8 \%$ ). La prison ferme est rarement renforcée par une amende (33 cas, soit $4,5 \%$ ). Après le 24 juillet 1889 , alors que cela est devenu possible, les procureurs ne signalent que 21 procédures civiles de déchéance de la puissance paternelle associées aux poursuites pénales. La pratique des tribunaux est le plus souvent entérinée par les cours d'appel. Sur les 60 prévenus qui sont jugés à nouveau à la suite de 51 procédures d'appel, ${ }^{(37)}$ 39 voient leur peine confirmée, 13 bénéficient d'un allégement et 8 , tous sur appel du parquet, connaissent une aggravation.

(36) Les pourcentages sont calculés sur la base de 731 inculpés, car nous ignorons la nature de la peine pour deux d'entre eux.

(37) Il faut ajouter 3 appels en cours. 
(38) Le sursis n'est applicable que dans les 174 affaires postérieures à la loi du 28 mars 1891 .
Tableau $n^{\circ} 4:$ nature de la peine définitive ${ }^{(38)}$

\begin{tabular}{c|c|c|c|c|c|c|c} 
& non-lieu & $\begin{array}{c}\text { acquit- } \\
\text { tement }\end{array}$ & $\begin{array}{c}\text { amende } \\
\text { seule }\end{array}$ & $\begin{array}{c}\text { prison } \\
\text { ferme }\end{array}$ & $\begin{array}{c}\text { prison } \\
\text { avec } \\
\text { sursis }\end{array}$ & $\begin{array}{c}\text { colonie } \\
\text { agricole } \\
\text { (mineur) }\end{array}$ & Total \\
\hline $\mathrm{nb}$ & 2 & 34 & 87 & 596 & 11 & 1 & 731 \\
$\%$ & 0,3 & 4,7 & 11,9 & 81,5 & 1,5 & 0,1 & 100
\end{tabular}

Effectifs cumulés : 731 sur 733 .

Tableau $n^{\circ} 5$ : quantum des peines de prison ferme

\begin{tabular}{c|c|c|c|c|c|c|c} 
& $\begin{array}{c}\text { de } 1 \\
\text { à } 15 \\
\text { jours }\end{array}$ & $\begin{array}{c}\text { >à 15 } \\
\text { jours et } \\
<2 \text { mois }\end{array}$ & $\begin{array}{c}\text { de 2 } \\
\text { à 5 } \\
\text { mois }\end{array}$ & $\begin{array}{c}\text { de } 6 \\
\text { à 23 } \\
\text { mois }\end{array}$ & $\begin{array}{c}2 \\
\text { ans }\end{array}$ & $\begin{array}{c}>\text { à } 2 \\
\text { ans }\end{array}$ & Total \\
\hline $\begin{array}{c}\text { effectifs } \\
\%\end{array}$ & 192 & 100 & 138 & 135 & 22 & 2 & 589 \\
$\begin{array}{c}\text { effectifs } \\
\text { prison }\end{array}$ & 32,6 & 17,0 & 23,5 & 22,9 & 3,7 & 0,3 & 100 \\
$\begin{array}{c}\% \\
\text { effectifs } \\
\text { peines }\end{array}$ & 26,3 & 13,7 & 18,9 & 18,5 & 3,0 & 0,3 & $81,5+$
\end{tabular}

* Effectifs cumulés : 589 sur un total de 596 (quantum inconnu dans 7 cas).

$*$ Effectifs cumulés : 731 sur un total de 733 .

+ Les 7 peines de prison ferme de durée inconnue sont réintégrées dans le $\%$ total.

Nota : les peines supérieures à 2 ans correspondent à un jugement d'assises (Rennes) et à une de 3 ans, mystérieusement prononcée en répression des articles 309 et suivants (Cour de Nancy, Tribunal de Saint-Dié, 11/04/1889).

Cette uniformité apparente masque en réalité des disparités importantes. Les normes en matière de violence à enfant sont en construction et des faits semblables peuvent donner lieu à des réactions divergentes, tant du côté de la magistrature que de la société civile.

\section{A) LES JUGES ET LES CATÉGORIES DE MALTRAITANCE}

L'usage des châtiments corporels fait partie des prérogatives de la puissance paternelle et personne ne remet véritablement en cause ce principe 
hérité du droit romain, même s'il n'est pas inscrit dans les codes. La question est donc de déterminer la frontière qui sépare l'exercice d'un droit de la commission d'un délit. En fait, de la lecture des jugements et des extraits de leurs attendus, il ressort que les magistrats classent les violences à enfants en trois catégories : l'exercice légitime du droit de correction, l'abus de ce droit légitime, enfin les violences illégitimes et délictueuses.

\section{$\left.1^{\circ}\right)$ Les châtiments "utiles au maintien de l'autorité"}

Dans la première catégorie, les magistrats estiment que le père (ou la mère) n'a fait qu'accomplir son devoir d'éducateur. Quand, selon l'expression d'un juge du tribunal de Cambrai, le responsable légal de l'enfant " n'a pas dépassé la mesure du droit de correction utile au maintien de son autorité $"{ }^{\left({ }^{39}\right)}$ il ne peut qu'être acquitté. C'est une situation rare et, sur les 35 acquittements $(4,8 \%)$ recensés, moins d'une dizaine ${ }^{(4)}$ relèvent de ce cas de figure qu'illustre bien une affaire jugée dans le ressort de la cour de Caen.

Le maire de Saint-Laurent-de-Terrigote alerte la gendarmerie : les époux T. maltraiteraient leur fillette de 2 ans. Les gendarmes se rendent sur place et découvrent "l'enfant couchée sur un mauvais grabat presque complètement dégarni de paille. Cette enfant qui paraissait fort chétive, portait aux cuisses et aux fesses des traces fort nombreuses et très apparentes de violences [les voisins ont souvent entendu des cris]. Pour se défendre, les époux T. alléguèrent qu'ils n'avaient fait qu'user du droit de correction envers leur enfant qui faisait constamment sous elle et était d'une malpropreté repoussante ". Le tribunal d'Avranches accepte l'argument et relaxe les parents. ${ }^{(41)}$

Nous avons là la marque d'un désaccord entre la société locale et l'instance judiciaire, désaccord que cette dernière évite en général de cultiver. En effet, une violence jugée illégitime par le maire, la gendarmerie, les voisins, n'a pu être régulée infrajudiciairement. Elle est légitimée par la Justice, qui avait été saisie au titre d'un recours suprême.

\section{$\left.2^{\circ}\right)$ Les abus du droit de correction}

La seconde catégorie est constituée par ce que le procureur général d'Orléans appelle, dans la lettre d'accompagnement qu'il rédige lors de
(39) Cour de Douai, Tribunal de Cambrai, 04/07/1891.

(40) Cet argument est explicitement utilisé 5 fois et peut avoir motivé 5 autres relaxes, dont 2 ont fait l'objet d'appels du parquet.

(41) Cour de Caen, Tribunal d'Avranches, 05/09/1891. 
(42) Cour d'Amiens, Tribunal de Clermont, 11/01/1890.

(43) Cour d'Angers, Tribunal de Segré, 1891. l'envoi des données recueillies dans le ressort de sa cour, "un abus du droit de correction paternelle ». Dans ce cas, ajoute-t-il, "les inculpés n'ont été punis que d'une simple amende ». Il évoque notamment la situation d'une jeune fille de 17 ans, enceinte, dont le mutisme face aux questions maternelles se traduisit par quelques coups de canne. Le tribunal de Gien condamne la prévenue à 1 franc d'amende.

Le jugement concerne donc aussi le mineur : pour qu'il y ait simplement " abus du droit de correction ", il faut que le principe de la punition soit fondé. L'inconduite de l'enfant doit être manifeste comme, par exemple, dans le cas de Henri L., un cordonnier veuf qui élève seul deux garçons de 6 et 7 ans : "Les enfants, abandonnés à eux-mêmes et d'un caractère indiscipliné, commettaient toutes sortes de méfaits et étaient l'objet de plaintes assez vives. Le père a dî̀, à différentes reprises, sévir contre eux, mais il a dépassé les limites de la correction paternelle.

Une enquête très minutieuse a été prescrite en vue de la déchéance de la puissance paternelle de L. Elle n'a pas apporté d'éléments suffisants pour justifier cette mesure; depuis la condamnation [à une amende de 15 francs], l'aîné des enfants a été placé par des personnes charitables et le plus jeune, qui n'est plus entraîné par son frère, fréquente régulièrement l'école ". ${ }^{(42)}$

Un comportement rebelle de l'enfant peut même justifier partiellement des exactions non dépourvues de gravité. Un maçon de 40 ans a, d'un premier lit, un fils âgé de 12 ans. "Il le maltraitait souvent, l'enfermait dans une cave et le privait même parfois de nourriture. Un jour on le vit ramener à la maison l'enfant qui s'était échappé. Il lui avait lié les mains derrière le dos et frappait à coups de bâton pour le faire marcher [...]. L'enquête a démontré que le jeune D. était d'une méchanceté incorrigible. C'est pourquoi le tribunal n'a infligé au prévenu que la peine légère de 24 beures d'emprisonnement ". ${ }^{(43)}$ Bien que l'amende soit ici transformée en une courte peine de prison, nous ne changeons pas de catégorie.

Les actes isolés, même s'ils ont une certaine gravité, sont intégrés à cette catégorie et punis d'une amende plus ou moins symbolique. Une femme en instance de divorce, mère de 5 enfants qu'elle "paraissait aimer ", corrige à l'aide d'une corde son fils de 9 ans parce qu'il a commis une maladresse. Ses bons antécédents lui valent de n’être condam- 
née qu'à une peine de 5 francs d'amende. ${ }^{(4)}$ Marie B., ménagère à Terrehault, "sous l'empire d'un mouvement de colère » et alors "qu'elle aimait ses enfants et les soignait bien", lance un couteau à sa fille de 9 ans et la blesse sérieusement au ventre. Elle doit payer 20 francs d'amende. ${ }^{(4)}$

\section{$\left.3^{\circ}\right)$ Violences illégitimes et délictueuses}

Avec la dernière catégorie nous rentrons dans le champ du "véritable" délit. Les résumés parlent d'objets contondants, de brutalités inadmissibles, de coups portés sans raison, ou rejettent les raisons invoquées par l'accusé comme constituant un prétexte irrecevable.

$\mathrm{Si}$, à quelques exceptions près, l'entrée dans cette catégorie se traduit par un passage en prison, l'échelle des peines est large - de 48 heures à 2 ans de prison - et n'est pas nécessairement proportionnelle à l'intensité des sévices.

\section{$\left.4^{\circ}\right)$ Le juge et le formalisme juridique}

Tout comme elle a une certaine autonomie par rapport aux intérêts économiques de la classe dominante, l'institution judiciaire a une certaine autonomie par rapport à "l'opinion publique". Elle peut en effet user des ressources du formalisme juridique et notamment mettre en avant le principe de la légalité des formes. Sur nos 35 acquittements, 11, dont 1 confirmé en appel (Chambéry), s'appuient sur des considérations purement juridiques. Le tribunal d'Epernay, par exemple, relaxe la dénommée Alphonsine G. malgré le constat du médecin, car « il n'y a pas de preuve autre que la parole de l'enfant ", lequel est âgé de 7 ans. ${ }^{(46)}$

Le tribunal d'Aix-en-Provence va beaucoup plus loin. Les époux G. avaient une petite fille de quatre ans. "Ces parents dénaturés laissaient seule, dans une mansarde du neuvième étage, sans soins, presque sans nourriture cette pauvre enfant maladive que la malpropreté, le miasmatisme de l'air ambiant, le froid, l'inanition devaient rapidement conduire à la mort ". Le tribunal acquitte "ces deux monstres par le motif que ces actes - quelque répréhensibles qu'ils fussent - ne paraissaient pas être juridiquement prévus par les articles 309 et suivants du code pénal ». ${ }^{(47)}$

Ce formalisme extrême est rare. Les cas de privation de soins sans violence directe concernant de très jeunes enfants sont réprimés avec autant 
(48) Nous parlons

bien de psychologie et non de psychiatrie.

(49) C'est nous qui soulignons.

(50) Cour de Nîmes, Tribunal d'Orange, 09/01/1890. voire plus de sévérité que les coups. L'usage du droit de correction paternelle n'est pas opposable et les peines descendent rarement sous les six mois quand l'enfant reste en vie. Sa mort aggrave la sentence.

La "fille" P. a eu 6 enfants naturels. Elle se livre à la débauche et à l'ivrognerie et 4 de ses enfants sont morts en bas âge, notamment la dernière née, à l'âge de trois ans. "La rumeur publique accusait la fille P. de laisser mourir ses enfants de faim et de manque de soins ". L'enquête établit " que l'enfant était mort d'athrepsie; il s'était éteint lentement, manquant de nourriture même grossière et de soins. L'enquête n'a établi aucun acte de violence directe ». La fille P. est condamnée à 2 ans de prison pour homicide par imprudence.

\section{$\left.5^{\circ}\right)$ Naissance d'une sensibilité "psychologique"}

Les tribunaux commencent-ils à prendre en compte des données d'ordre psychologique ? ${ }^{(48)}$ Elles viennent étayer les motivations d'un jugement rendu par le tribunal d'Orange.

Une fillette de 9 ans rentre tard d'une course au village voisin. " $A$ son retour, T. lui attache les mains derrière le dos et, passant l'extrémité de la corde sur une poutre de la cuisine, il raidit le lien assez fortement pour empêcher la jeune Denise de pouvoir s'asseoir. Après quoi il va se coucher, laissant ainsi l'enfant attachée dans une pièce sans feu et sans lumière ". La corde cède et l'enfant s'enfuit. "Il a été constaté que l'enfant avait également reçu des coups assez violents qui avaient laissé des traces principalement aux cuisses. Des renseignements recueillis il résulte que le nommé T. n'a jamais témoigné à cette fille le même attachement qu'à ses autres enfants; le motif de cette antipathie vient de ce que la petite Denise n'a jamais été nourrie par sa mère. ${ }^{(49)}$ L'enfant abandonnée à elle-même a contracté des habitudes vicieuses; quelques larcins ont été relevés à sa charge. Cette circonstance, jointe aux bons renseignements fournis sur l'inculpé par les autorités locales, a autorisé le tribunal à abaisser le peine corporelle dans des limites qui, au premier abord, sont faites pour surprendre ". ${ }^{(50)}$

Le père n'a été condamné en effet qu'à 24 heures de prison. Il est vrai aussi que nous avions affaire à un propriétaire bénéficiant du soutien des autorités locales et non à un journalier de mauvaise réputation. Nous retrouvons là des circonstances qui jouent aussi dans les affaires dites "de mœurs". 


\section{B) A JUST MEASURE OF PUNISHMENT ${ }^{(51)}$}

\section{$\left.1^{\circ}\right)$ Des catégories fluctuantes}

Les catégories que nous avons définies ne sont pas dépourvues de laxité. Les magistrats peuvent classer différemment des actes très proches.

Selon le maire de son village, Rosalie B., aubergiste de son état, "battait fréquemment ses deux petites filles, [âgées de deux ans et demi et de dixhuit mois] avec assez de violence pour faire couler le sang ". Le tribunal de Mamers (Sarthe) " acquitta la prévenue, estimant qu'elle n'avait pas dépassé les droits de correction paternelle ". ${ }^{(52)}$

Léon S., vannier à La Cour dans la Somme, est condamné à 16 francs d'amende pour avoir "À plusieurs reprises frappé sa fille à l'aide de baguettes d'osier avec une violence telle que ces coups ont laissé des traces pendant plusieurs jours sur le corps de l'enfant ". ${ }^{(3)}$

Florine H., qui frappe ses enfants de 11 et 13 ans « à l'aide d'une baguette de bouleau jusqu'à ce que le sang jaillit ", voit le tribunal de Beauvais (Oise) lui infliger trois mois de prison. ${ }^{(54)}$

Le rapprochement de ces trois affaires montre bien que les seuls faits objectifs comme la force, la nature ou la fréquence des coups ne fondent pas, au niveau juridique, la séparation entre l'exercice normal du "droit de correction" et violence délictueuse. En fait, la seule trace de cohérence nationale en matière de répression des violences à enfants concerne la correctionnalisation : elle est quasi systématique.

Le tribunal d'Angoulême juge et condamne à un an de prison un cultivateur de 47 ans qui martyrisait son fils de 13 ans : «L. maltraitait journellement et privait de nourriture son fils. Alphonse (coup à la tête avec chenet, oreille décollée); pour apaiser sa faim, le jeune garçon était obligé de demander du pain aux voisins; son père le faisait coucher dans une cave, le jour il l'enfermait dans le poulailler; le 20 avril, Alphonse L. mourut; son corps était couvert de plaies $"{ }^{(5)}$ L'enfant est mort à la suite des mauvais traitements subis. Les assises étaient envisageables. La correctionnalisation a-t-elle été choisie pour assurer une condamnation minimale? L'hypothèse est plausible. Il n'en demeure pas moins que cette politique ne débouche pas sur un semblant d'homogénéisation des sentences, ni même sur une disparition des "acquittements scandaleux". ${ }^{(5)}$ Même les violences les
(51) Allusion et

hommage au livre de

Michael IGNATIEFF,

A Just Measure of Pain :

The Penitentiary in the

Industrial Revolution, New

York, Pantheon, 1978.

(52) Cour d'Angers, Tribunal de Mamers, 28/11/1888.

(53) Cour d'Amiens, Tribunal de La Cour, 07/03/1891.

(54) Cour d'Amiens, Tribunal de Beauvais, 28/11/1888.

(55) Tribunal d'Angoulême, Cour de Bordeaux, 06/06/1889.

(56) L'erratisme des jugements d'assises est le principal justificatif du mouvement de correctionnalisation qui se développe tout au long du XIXe siècle. Voir Michelle PERROT, Philippe ROBERT, Introduction au compte général de l'administration de la justice criminelle en France pendant l'année 1880, Paris, ChampionSlatkine, 1989, p. 15-16. 
(57) Cour de Lyon, 01/07/1890. plus graves, celles que nous jugeons aujourd'hui unanimement monstrueuses, sont très inégalement sanctionnées.

\section{$\left.2^{\circ}\right)$ Les juges et les violences extrêmes}

Eugène B., 45 ans, menuisier à Lyon, martyrise son fils de dix ans, également prénommé Eugène. Alerté par les voisins le commissaire mène une enquête au domicile de la famille B. : " il trouva le jeune B. Eugène, âgé de 10 ans, couché sur le sol d'une soupente dans un état complet de nudité. L'enfant était attaché par le cou au moyen d'une chaîne de fer de 20 $\mathrm{cm}$ de longueur environ et dont l'extrémité était fortement rivée au plancher. En outre, le malheureux avait les mains liées derrière le dos par une double corde, ce qui rendait tout mouvement impossible. L'enfant est resté nuit et jour dans cette position pendant une semaine. Son père ne le visitait que pour lui donner des coups de pied et de canne. Sa mère venait le voir pour lui apporter de la nourriture; elle a semblé s'apitoyer sur son enfant, mais elle a été dans l'impossibilité de le soustraire à ces violences graves sans dénoncer son mari qu'elle redoutait et qui avait toujours sur lui la clé du cadenas de la chaîne en fer. Ces mauvais traitements ont été employés plusieurs fois, toujours avec la même rigueur, dès que l'enfant commettait la plus petite faute ". ${ }^{(57)}$

Le tribunal correctionnel condamne ce bourreau à deux ans de prison et le tribunal civil le déchoit de sa puissance paternelle. La cour d'appel confirme le jugement dans son arrêt du 1er juillet 1890. Le rédacteur du résumé ne manque pas de relever "la gravité exceptionnelle du délit ", afin de justifier cet usage de la peine maximale. On pourrait penser que, devant ces actes de barbarie, la justice, sans être uniforme, se montre globalement sévère. Ce n'est que partiellement vrai puisque, outre 4 acquittements et 7 condamnations excluant la prison ferme (sursis ou amende), 70 auteurs de sévices particulièrement graves passent moins de six mois derrière les barreaux. Comment expliquer cette relative clémence? 
Tableau $n^{\circ} 6$ : Condamnations prononcées pour le 143 affaires où des actes de barbarie ont été commis

\begin{tabular}{|c|c|c|c|c|c|c|c|c|}
\hline & $\begin{array}{l}\text { pas de } \\
\text { prison } \\
\text { ferme }\end{array}$ & $\begin{array}{c}1 \text { à } 15 \\
\text { jours de } \\
\text { prison }\end{array}$ & 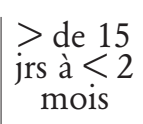 & $<\underset{\text { mois }}{2 \text { à }} 6$ & $\underset{\text { mois }}{6 \text { de } 24}$ & $\begin{array}{c}2 \\
\text { ans }\end{array}$ & $\begin{array}{l}>\text { de } \\
2 \text { ans }\end{array}$ & Total \\
\hline $\begin{array}{c}\text { effectifs } \\
\text { hommes }\end{array}$ & 5 & 9 & 13 & 11 & 21 & 3 & 1 & 63 \\
\hline $\begin{array}{l}\text { effectifs } \\
\text { cumulés }\end{array}$ & 5 & 14 & 27 & 38 & 59 & 62 & 63 & 63 \\
\hline $\begin{array}{c}\% \\
\text { hommes }\end{array}$ & 7,9 & 14,3 & 20,6 & 17,8 & 33,3 & 4,8 & 1,6 & 100 \\
\hline $\begin{array}{c}\% \\
\text { cumulés }\end{array}$ & 7,9 & 22,2 & 42,8 & 60,3 & 93,6 & 98,4 & 100 & 100 \\
\hline $\begin{array}{l}\text { effectifs } \\
\text { femmes }\end{array}$ & 6 & 17 & 9 & 13 & 23 & 11 & 1 & 80 \\
\hline $\begin{array}{l}\text { effectifs } \\
\text { cumulés }\end{array}$ & 6 & 23 & 32 & 45 & 68 & 79 & 80 & 80 \\
\hline $\begin{array}{c}0 \% \\
\text { femmes }\end{array}$ & 7,6 & 21,3 & 11,3 & 16,3 & 28,7 & 13,6 & 1,2 & 100 \\
\hline $\begin{array}{c}\% \\
\text { cumulé }\end{array}$ & 7,6 & 28,9 & 40,2 & 56,5 & 85,2 & 98,8 & 100 & 100 \\
\hline $\begin{array}{l}\text { effectifs } \\
\text { totaux }\end{array}$ & 11 & 26 & 22 & 24 & 44 & 14 & 2 & 143 \\
\hline
\end{tabular}

La moyenne des peines (hors 7ème colonne) est de 5 mois et 20 jours pour les hommes et de 6 mois et 27 jours pour les femmes. L'intégration des peines supérieures à 2 ans accentuerait l'écart, puisqu'il s'agit d'une condamnation d'un homme à 36 mois de prison et d'une sentence de travaux forcés à perpétuité qui touche une femme... Rappelons que les femmes, à délit égal, sont généralement moins condamnées que les hommes. Cette exception tient probablement à la nature du délit qui, plus encore qu'à l'encontre de loi, va à l'encontre de l'idée que les magistrats se font de la nature féminine.

Jean-Clément Martin, qui a mené une enquête sur les violences sexuelles dans le bocage vendéen, rappelle qu'une affaire judiciaire peut "être exposée selon trois niveaux de réalité: un événement se produit, renvoyant à l'état d'une société locale, aux histoires individuelles; un jeu collectif se met en 
(58) Jean-Clément MARTIN, "Violences sexuelles, pratiques de l'histoire", in Annales, mai-juin 1996, n³, pp. 660-661.

(59) Voir en particulier sur ce thème : Alain CORBIN, Le Village des cannibales, Paris, Aubier, 1990, 204 p. et Frédéric CHAUVAUD, De Pierre Rivière à Landru. La violence apprivoisée au XIXe siècle, Bruxelles, Brépols, 1991, 271 p. et Les Passions villageoises au XIXe. Les émotions rurales dans les pays de Beauce, du Hurepoix et du Mantois, Paris, Puplisud, 1995, 271 p.

(60) Michel CHAUVIÈRE, Pierre LENOEL, Eric PIERRE, Protéger l'enfant. Raison juridique et pratiques socio-judiciaires (XIXe-XXe siècles), Rennes, Presses Universitaires de Rennes, 1996, 183 p.

(61) Jacques POSTEL, Claude QUÉTEL (ed), Nouvelle histoire de la place pour aboutir à l'instruction et au procès, renvoyant aux relations entre la société locale, sa représentation de la loi et de l'État, et avec les représentants de l'État; des individus dans le système judiciaire (juges, jurés, puis législateurs) intègrent l'événement dans leurs normes et l'estiment important selon leurs objectifs de contrôle et de régulation de la société ". ${ }^{(58)}$ À chaque niveau de cette réalité, de multiples causes concourent à l'évolution des pratiques judiciaires : modification de la sensibilité - notamment un nouveau regard sur la cruauté et la violence ${ }^{(59)}$-, transformation de la vision de l'enfance en général et de l'enfance "en danger" en particulier, ${ }^{(60)}$ apparition de nouveaux concepts dans le champ médico-psychologique ou criminologique, ${ }^{(61)}$ conceptions nouvelles des rapports intrafamiliaux ${ }^{(62)}$ et de l'exercice de la puissance paternelle, ${ }^{(63)}$ etc. L'existence de cette enquête, marque de l'émergence d'une "conscience d'avoir à légiférer", ${ }^{(64)}$ souligne l'évolution des normes en cours et l'apparition de nouveaux objectifs de contrôle et de régulation. Les écarts entre des arrêts concernant des faits voisins, surprenants pour le lecteur actuel, sont révélateurs des changements en marche et de leur dimension locale. Pour comprendre l'activité d'un tribunal, il faut sortir du palais de justice, prendre contact avec la société locale, ses réseaux de sociabilité et de pouvoir, ses façons de penser et de voir le monde.

\section{C) LES VIOLENCES À ENFANTS,}

\section{LA SOCIÉTÉ LOCALE ET LA JUSTICE \\ $\left.1^{\circ}\right)$ Géographie du contentieux}

Les affaires sont très inégalement réparties sur le territoire national : les 14 départements les plus actifs concentrent la moitié des affaires, le dernier quartile rassemble 55 départements (carte $n^{\circ} 1$ ).

Les départements du Sud et du Centre connaissent rarement plus de 5 affaires (carte $\left.n^{\circ} 2\right)$.

Les tribunaux du Tarn-et-Garonne, de l'Ariège, de l'Aude et des Alpesde-Haute-Provence n'en jugent même aucune. Avec 33 affaires, la Seine-Maritime arrive en tête, mais les résultats sont faussés par les chiffres parisiens (la Seine totalise 21 affaires, mais sur la seule année 1891). Si nous passons de l'échelle départementale à l'échelle des cours 
CARTE $\mathrm{N}^{\circ} 1$

RÉPARTITION DES AFFAIRES

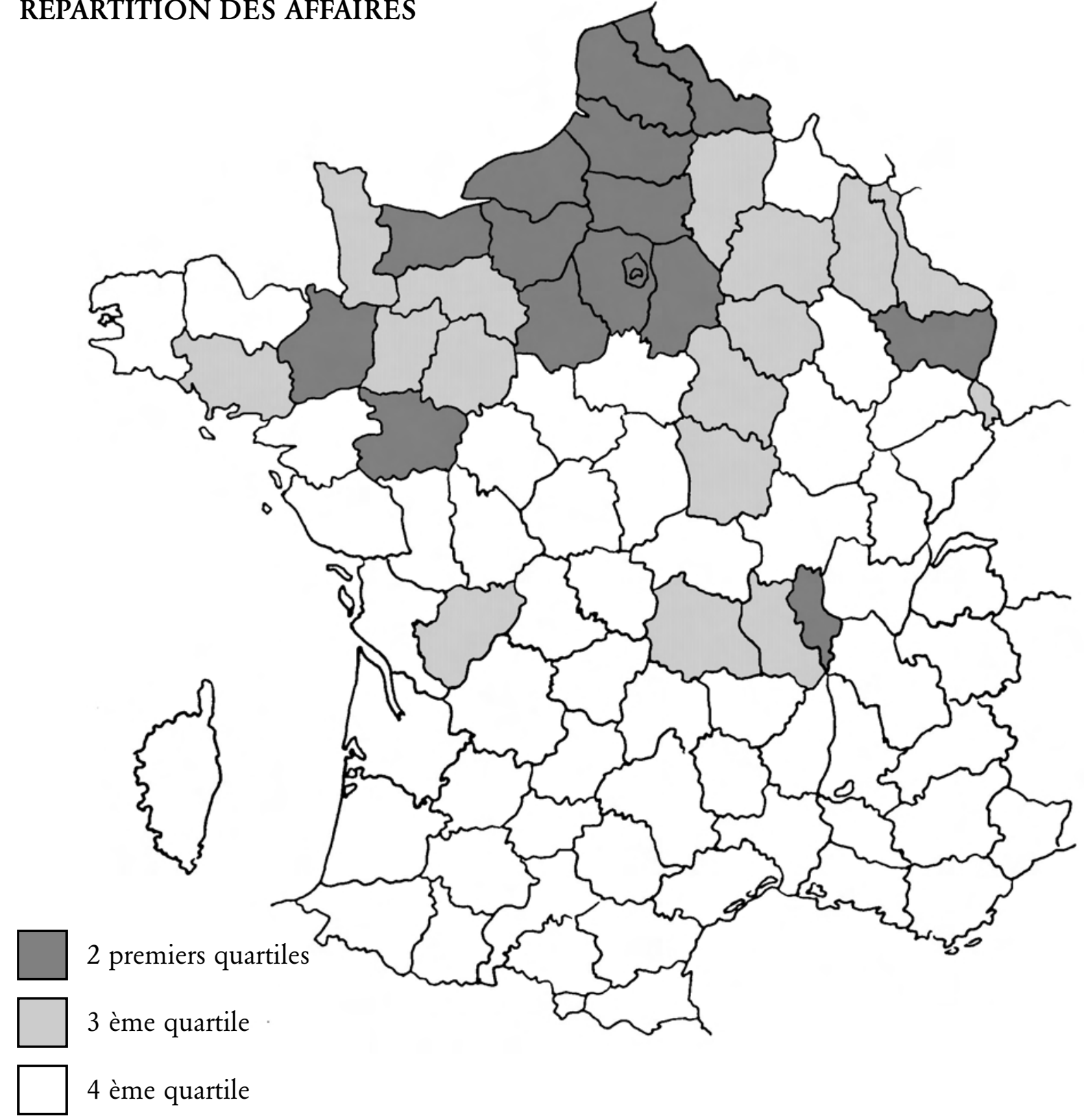


CARTE $\mathrm{N}^{\circ} 2$

NOMBRE D'AFFAIRES

PAR DÉPARTEMENT
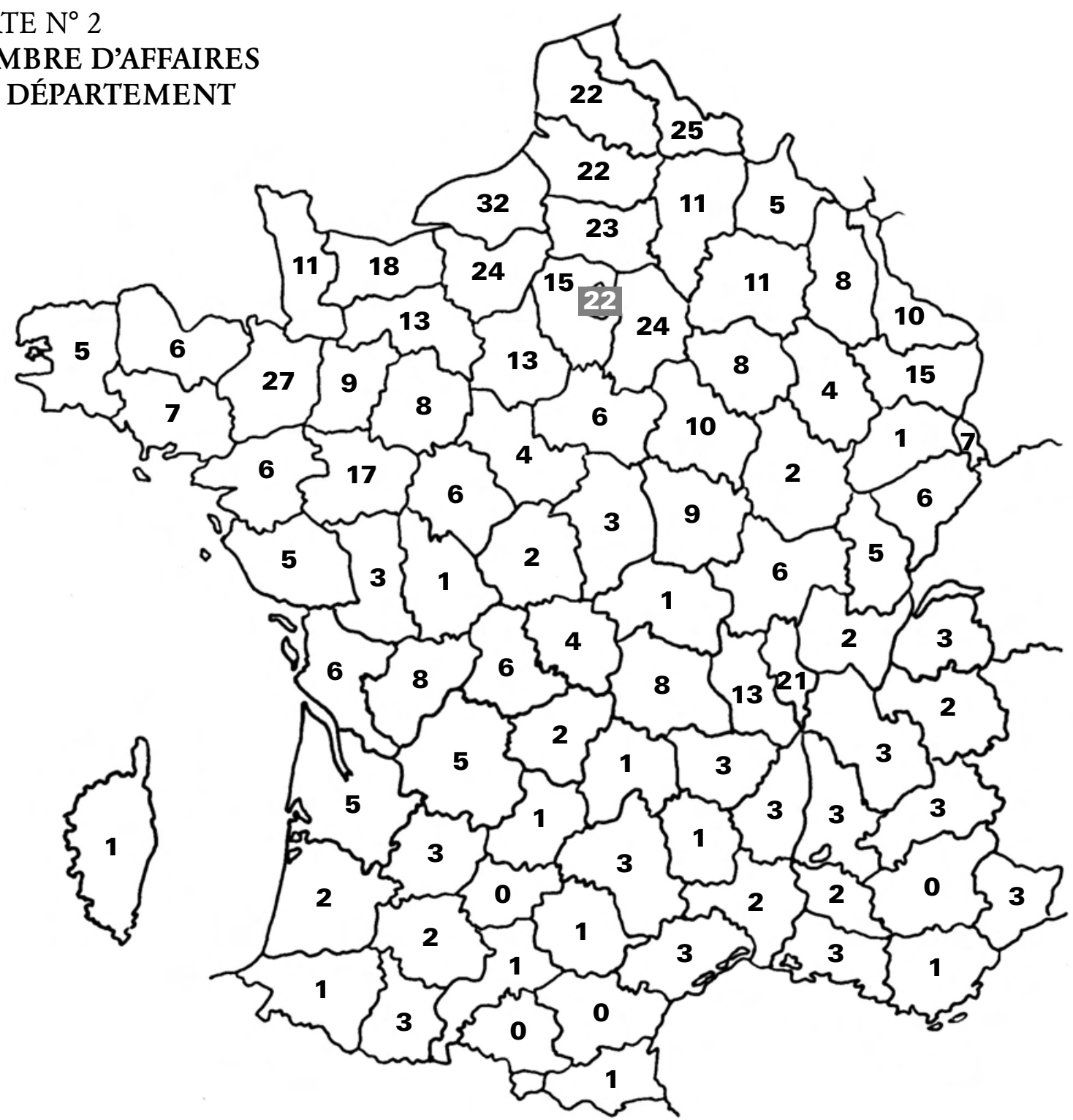
CARTE $N^{\circ} 3$

RÉPARTITION DES AFFAIRES

PAR COUR D'APPEL

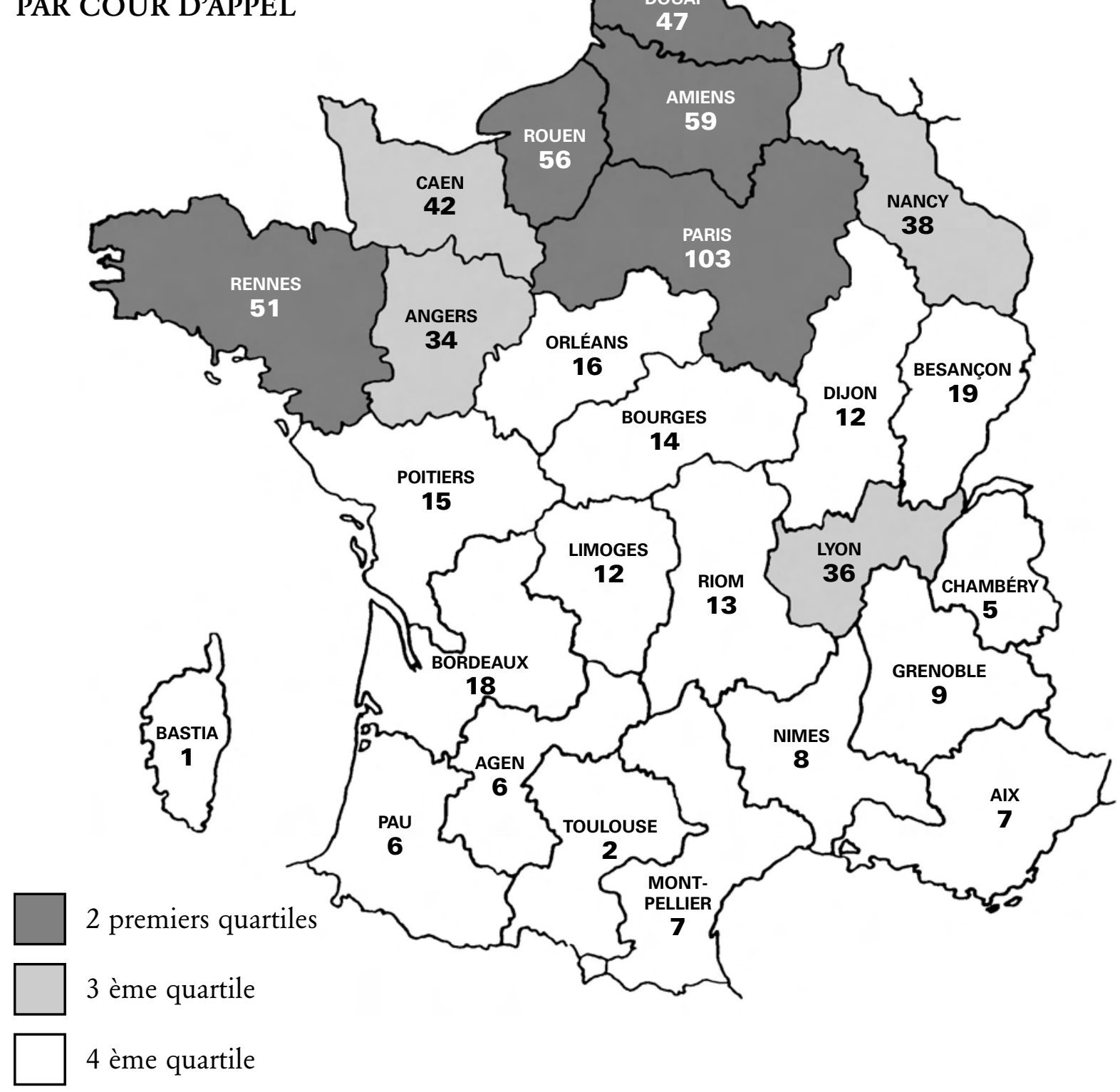


psychiatrie, Toulouse,

Privat, 1983, 774 p. et Laurent MUCCHIELLI

(ed), Histoire de la criminologie française, Paris, L'Harmattan, 1994, 535 p.

(62) Une bonne synthèse dans François de SINGLY (ed), La Famille, l'état des savoirs, Paris, la Découverte, 1991, 448 p.

(63) Le succès du livre de Gustave DROZ, Monsieur, madame et bébé, Paris, Hetzel, 1866, est une marque de ces transformations qui touchent en premier lieu la famille bourgeoise.

Notre exemplaire date de 1868 et est présenté comme la 28ème édition.

(64) Nous empruntons ce concept à Jacqueline BERNAT de CELIS, Fallait-il créer un délit d'usage illicite de stupéfiants?, Paris, CESDIP, 1992, 241 p.

(65) La cour peut sembler être la bonne d'appel (carte $\left.{ }^{\circ} 3\right){ }^{\left({ }^{(6)}\right)}$ nous ne modifions pas fondamentalement la carte du contentieux et la prédominance du Nord et de l'Ouest (Bretagne et Normandie) demeure.

La différence du "poids" démographique des départements ne peut expliquer ces écarts : les Bouches-du-Rhône (3 affaires), l'Isère (3 affaires) ont une population comparable à la Somme (22 affaires) ou à l'Ille-et-Vilaine (27 affaires); la Gironde (5 affaires) n'est pas moins peuplée que la Seine-Maritime (33 affaires). ${ }^{\left({ }^{6}\right)}$ La traditionnelle opposition ville-campagne ne fournit aucune indication. Les taux d'urbanisation du Var (1 affaire) ou de l'Hérault (3 affaires) sont supérieurs à ceux de l'Oise (24 affaires) ou de l'Eure (25 affaires). ${ }^{(6)}$

Les violences intrafamiliales se déroulent le plus souvent dans le secret du sweet (!) bome. Pour son information la justice dépend, en cette matière plus qu'en toute autre, de la collaboration de l'environnement local. Autant que nous puissions en juger, ${ }^{(6)}$ les voisins, directement $(45,9 \%)$ ou par l'intermédiaire d'une rumeur publique bien orchestrée $(20,7 \%)$, sont à l'origine de la majorité des saisines. Les maires, qui alertent la justice dans $6,2 \%$ des cas, complètent le dispositif de "veille sociale". La victime $(10,7 \%)$ et sa famille $(12,4 \%)$ forment la seconde source d'informations pour la justice; les forces de l'ordre (pour l'essentiel gendarmes et gardes-champêtres) ne comptent que pour 3,3\%. Le nombre des poursuites, leur répartition géographique reflètent donc plus l'attitude d'un environnement que l'efficacité d'une politique pénale... ou que les violences réellement exercées contre les enfants.

Or, si la frontière entre le "droit de correction" et l'usage inacceptable de la force varie d'un tribunal à l'autre, ${ }^{\left({ }^{(9)}\right.}$ elle sera tout autant mobile d'une région à l'autre et même d'un individu à l'autre. De plus, le comportement des témoins n'est pas homogène, même quand la réprobation est unanime. Il oscille entre opprobre muet et dénonciation formelle aux autorités, à laquelle s'ajoute parfois une intervention directe "pour faire cesser un scandale ", comme à Auxerre où les voisins défoncent la porte de Léonie R. qui "roue de coups son enfant avec un manche à balai ». ${ }^{(70)}$ 


\section{$2^{\circ}$ ) Géographie de la peine}

La sévérité des cours peut être évaluée en prenant comme indicateur le nombre moyen de jours de prison ferme prononcés en dernière instance. Nous trouvons des peines moyennes supérieures à 4 mois (120 jours) dans 6 cours (Bordeaux, Rennes, Orléans, Caen, Dijon, Douai). À Paris, Lyon, Nancy, Angers, Montpellier et Aix, elles sont comprises entre 4 et 3 mois. À Riom, Amiens, Rouen, Nîmes et Agen, elles dépassent les 2 mois. À Grenoble, Besançon, Bourges, Pau, Limoges, Poitiers, Toulouse, Chambéry et Bastia l'incarcération dure en moyenne entre 50 et 2 jours. Ces calculs, qui portent sur des effectifs faibles, sont à prendre avec précaution. Par exemple, le "score" relativement élevé de Montpellier intègre la condamnation, par le tribunal de Rodez, à 2 ans (730 jours), du dénommé Pierre V. qui a brutalisé sa fille de 18 ans... et sa mère de 80 ans. ${ }^{(71)} \mathrm{Il}$ est permis de penser que, dans ce verdict, les violences sur ascendant ont pesé plus lourd que les violences sur descendant, d'autant que le même tribunal condamne peu après la veuve R., qui bat fréquemment sa fille handicapée mentale, à 6 jours de prison. ${ }^{(2)}$ Si nous excluons cette sentence maximale aux motivations ambiguës, la moyenne montpelliéraine tombe à 11 jours. Autrement dit, le faible nombre d'affaires par département ne permet guère une analyse factorielle de correspondances éclairante. Nous pouvons cependant essayer de comprendre certaines cohérences régionales ou départementales, là où elles existent, car l'erratisme reste le caractère essentiel des décisions de justice en matière de violence à enfant.

\section{$\left.3^{\circ}\right)$ La Savoie ou la violence acceptée?}

La région savoyarde ne connaît apparemment que 4 affaires correctionnelles de violence à enfant. Si le sieur François P. a bien donné quelques coups de poing à ses filles, c'est surtout parce qu'il montrait ses fesses devant chez lui qu'il est poursuivi à l'instigation du maire. ${ }^{(3)}$ La comparution de la veuve M. devant le tribunal de Saint-Jean-deMaurienne et sa condamnation à 3 jours de prison sont dues tout autant aux insultes en direction du garde champêtre qu'aux gifles sans gravité qu'elle asséna à sa fille. ${ }^{(7)}$ Ces deux jugements ne répriment donc que marginalement des violences à enfants.

"unité de compte", à la

fois pour avoir des

chiffres plus significatifs

et parce que le procu-

reur général est le relais

de la politique judiciaire

du ministère. Les écarts

de pratique entre tribu-

naux d'une même cour

obère quelque peu cette

logique statistique.

(66) Jacques

DUPÂQUIER (dir.),

Histoire de la population

française ; 3. De 1789

à 1914, Paris, PUF,

1988, p.139.

(67) Ibid, p. 204.

(68) Nous ne connaissons l'origine de l'information de la justice que dans 242 affaires.

(69) Même constat

chez Anne-Marie

SOHN, Chrysalides.

Femmes dans la vie privée

(XIXe-XXe siècles), Paris,

Publications de la

Sorbonne, 1996, p. 413.

(70) Cour de Paris,

Tribunal d'Auxerre,

21/07/1891. Sur ce

point, voir notre com-

munication "Les 
Violences à enfants en milieu rural”, in Actes $d u$ colloque de Poitiers, à paraître. Nous avons pu constater un certain recul de "l'indifférence" en comparant nos résultats à ceux de Frédéric CHAUVAUD, Les Passions villageoises..., op. cit.

(71) Cour de Montpellier, Tribunal de Rodez, 01/05/1891. Jugement confirmé en appel.

(72) Ibid., le

14/01/1892. Ce jugement hors temps n'a pas été intégré dans nos statistiques.

(73) Cour de Chambéry, Tribunal de Bonneville, déc. 1891.

(74) Cour de Chambéry, Tribunal de Saint-Jean-de-

Maurienne, 29/12/1891.

(75) Cour de

Chambéry, Tribunal de Chambéry, 23/01/1891.

(76) Cour de Chambéry, Tribunal d'Annecy (assises), 30/01/1890.
Quand les autorités n'ont pas constaté directement les faits, les témoignages sont difficiles à réunir. La femme $\mathrm{F}$. frappe son beau-fils de 17 ans et sa belle-fille de 15 ans avec un bâton et un trident : "Lesfaits attestés par plusieurs témoins à charge ont été démentis par des témoins à décharge. C'est cette dernière circonstance qui a motivé le jugement d'acquittement". Il sera confirmé en appel. ${ }^{(75)}$

Dans une région où les condamnations pour coups et blessures pour 100000 habitants sont supérieures à 100 et où les crimes contre les personnes sont nombreux, les situations de violence intrafamiliale arrivent difficilement aux oreilles de la justice. La société locale admet-elle plus facilement l'usage de la brutalité comme méthode éducative ou comme mode de gestion des conflits domestiques que l'intrusion des autorités judiciaires dans le huis clos familial ? L'attitude des jurés populaires dans une procédure criminelle milite pour cette hypothèse.

"F., rentrant chez lui vers 2 b du matin, le 22 septembre 1889, saisit sa femme qui était assise auprès du poêle et à l'aide d'un mouchoir s'efforça de l'attacher au pied du lit dans lequel étaient couchés ses cinq enfants. Sa victime ayant résisté, F. lui donna plusieurs soufflets et détacha du plafond, où il était suspen$d u$, un fusil chargé et armé; alors, son fils Octave, âgé de douze ans, se leva et essay a d'arracher l'arme des mains de son père. Dans la lutte, le père fit tomber le jeune Octave à diverses reprises. Cet enfant se blessa grièvement à la tête. Marie-Françoise, âgée de 9 ans, et Émile, âgé de 11 ans, s’élancèrent au secours de leur frère Octave et furent à leur tour bousculés et repoussés.

F. poursuivit encore sa femme dans la cuisine et lui porta plusieurs coups avec son fusil dont il se servait comme d'une massue. Il revint dans la chambre où étaient ses enfants et porta au jeune Octave un coup de crosse qui ne l'atteignit pas, mais qui eut pour effet de projeter sur le lit un outil de charpentier placé sur une planche; l'un des enfants fut blessé à la tête par cet outil.

Le père s'acharna encore à frapper avec son fusil François et Octave; celui-ci fut si grièvement atteint qu'il succomba aux suites de ses blessures, le 4 octobre.

F. était donc poursuivi pour coups et blessures sur la personne de sa femme et sur celles de ses enfants, avec cette circonstance, en ce qui concernait son fils Octave, que les coups, portés sans intention de donner la mort, l'avaient cependant causée. Il bénéficia d'un verdict d'acquittement, le 30 janvier 1890 ». ${ }^{(7)}$ 
Julien, 20 mois, fils d'une bouchère de Bonneville, est frappé constamment et "manque des soins les plus élémentaires». Sa mère est condamnée à quinze jours de prison. ${ }^{(77)}$ Dans la seule condamnation pour maltraitance "pure" de la région savoyarde, le tribunal se montre plutôt clément. Le faible taux de contentieux va de pair avec une certaine douceur des peines (moins de 5 jours en moyenne).

Il semble donc que, dans le ressort de la cour de Chambéry, la tolérance de la société civile face aux violences "éducatives" ne soit pas vraiment contrariée par la politique pénale des tribunaux ou de la cour.

\section{$\left.4^{\circ}\right)$ Rennes ou la violence refusée?}

Avec 27 affaires ( 26 correctionnelles, 1 criminelle), le département de l'Ille-et-Vilaine arrive en deuxième position et nous pourrions penser que ce département breton est l'un des plus violents de France. C'est possible, même si le compte général de la justice criminelle nous dit le contraire. Par contre, nous pouvons constater que, d'une part, la justice semble trouver facilement des informateurs et des témoins ${ }^{(78)}$ et que, d'autre part, les tribunaux correctionnels d'Ille-et-vilaine se montrent particulièrement sévères (207 jours de prison ferme en moyenne). Ils ont par ailleurs une politique cohérente; autant qu'on puisse en juger sur la base de résumés, les peines sont proportionnelles à la gravité des sévices. De Redon à Saint-Malo en passant par Rennes et Fougères, y a-t-il convergence entre les habitants et la magistrature pour sanctionner les bourreaux d'enfants? L'affaire "Francine" le laisse penser.

Francine, une jeune débile d'une vingtaine d'années, est privée de soins et gravement maltraitée. À la suite d'un déménagement qui la prive de la protection du voisinage, elle meurt au début de l'année 1888 d'une congestion pulmonaire aggravée par le défaut de soins et de nourriture. Délaissant les articles 309 et suivants, ou 319 et 320, le parquet et le juge d'instruction renvoient les prévenus devant la cour d'assises de Rennes sous l'inculpation de séquestration avec tortures corporelles ayant duré plus d'un mois et d'homicide involontaire. Le jury populaire acquitte le père, qui n'a pas pris de part active au calvaire de Francine, mais condamne la belle-mère aux travaux forcés à perpétuité.
(77) Cour de

Chambéry, Tribunal de

Bonneville, 22/08/1890.

(78) Les voisins d'Émile

D. et d'Henriette T., ou ceux de Louise C.,

n'hésitent pas à saisir le commissaire de

Fougères. Quant aux témoins des violences de Charles D. sur sa fille de 2 ans et demi, ils vont jusqu'à s'interposer physiquement entre l'enfant et son bourreau avant de le désigner aux forces de l'ordre. Toutes ces affaires sont jugées par le tribunal de Fougères entre 1889 et 1891 . 
(79) Cour d'assises de Rennes, 18/02/1888.

(80) Cour de Lyon, Tribunal de Rouanne, 26/08/1887.

(81) Ibid., 21/06/1889.

(82) Ibid., 29/03/1889.

(83) Ibid., 09/12/1887.

(84) Ibid., 23/05/1890, pour une affaire semblable, où le prétexte (course mal faite) était le même, le tribunal de Saint-Quentin prononce une peine de 4 mois.
L'institution judiciaire, les voisins/témoins, les jurés populaires se sont unis pour rendre un verdict exemplaire. ${ }^{(79)}$

\section{$\left.5^{\circ}\right)$ La clémence des magistrats roannais}

La veuve C. brutalise ses deux enfants, surtout sa fille de 6 ans. Elle la frappe " au moyen d'un pique-feu. Visitée par le médecin, il a été constaté que le corps de la petite fille était littéralement couvert d'ecchymoses et de contusions résultant de coups qu'elle avait reçus. La veuve C. n'a été condamnée le 6 juillet 1888 qu'à 15 jours de prison $» .{ }^{(80)}$

"La fermme C., déjà condamnée le 6 juillet 1888 à 15 jours de prison pour coups et blessures envers ses enfants, continua à les brutaliser. La petite Marie, agée de 6 ans, était surtout l'objet de sa baine. Elle inventa de véritables tortures contre cette enfant qui, à la suite de mauvais traitements et d'un manque absolu de soins, ne tarda pas à dépérir. Un jour la mère prit un pique-feu de $80 \mathrm{~cm}$ de longueur et en asséna un coup vigoureux sur la tête de la pauvre petite. Le sang jaillit. Transportée à l'hôpital, l'enfant mourut le 19 mai 1889. Elle succomba à la phtisie qui la minait depuis longtemps, mais le médecin ajouta que, si les mauvais traitements n'avaient pas engendré la maladie, des soins hygiéniques et rationnels auraient pu en retarder le développement. Le tribunal ne l'a condamnée, le 21 juin 1889, qu’à 10 jours de prison, alors que précédemment elle avait été condamnée à 15 jours ». ${ }^{(81)}$

Antoinette V., femme M., martyrise sa fille de 12 ans. Les voisins portent plainte. L'enquête révèle que l'enfant est "foulée aux pieds et frappée à coups de poing. Frappée également au moyen d'un manche un balai de grosseur moyenne [...], cassé sous la violence des coups. [Elle était] privée de nourriture et on l'avait vu dérober aux poules les pelures de pommes de terre qui leur étaient jetées. Sa mère [...] l'attachait à une chaise, les mains liées derrière le dos [...]. Cette enfant était mal habillée et grelottait de froid dans une chambre sans feu. [Immobilisée, elle est] obligée de faire sous elle. Le tribunal ne l'a condamnée qu'à dix jours de prison $»{ }^{\left({ }^{(82)}\right.}$ Devant le même tribunal, à la même époque, des coups de bâton sur un enfant de dix ans valent 3 francs d'amende à une mère de famille. ${ }^{(83)}$ Un père, violent et alcoolique, tente d'étrangler son fils de 6 ans et le frappe au point de l'envoyer à l'hôpital «parce qu'il n'avait pas trouvé de fromage blanc ». Il passe 10 jours en prison. ${ }^{(84)}$ Dans 
toutes ces affaires, des voisins ou des parents ont alerté les autorités, témoigné devant le tribunal. La légèreté des peines, que déplore le rédacteur des notices, tient donc au bon vouloir des magistrats roannais.

Anne-Marie Sohn évoque un droit de correction "strictement encadré par l'opinion et la jurisprudence, constante pour toute la IIIe République». Toute atteinte à l'intégrité physique des enfants serait unanimement réprouvée par la vox populi et châtiée par la justice. ${ }^{(85)}$ Si cette "jurisprudence" est déjà à l'œuvre en Ille-et-Vilaine ou, dans une moindre mesure, en Gironde, elle n'est pas même ébauchée dans la région savoyarde. Dans la majorité de l'hexagone, "la persistance de l'ancien régime" coexiste avec l'expression de la nouvelle sensibilité et les décisions de justice sont imprévisibles. L'attitude ambiguë de la justice ne concerne pas que les auteurs; elle s'applique aussi aux victimes.

\section{D) ENFANTS VICTIMES OU ENFANTS COUPABLES : LES AMBIGUÏTÉS DE LA JUSTICE}

L'idée que les enfants coupables pourraient aussi être des enfants victimes est en plein essor en cette fin de XIXe siècle. Elle triomphera d'ailleurs d'une certaine façon dans la loi de 1898, quand le sénateur Bérenger introduira un amendement qui parle des "enfants victimes ou auteurs". La lecture de nos archives nous incite à penser que l'équation est commutative et que, derrière l'enfant victime, le magistrat voit facilement un enfant coupable qu'il faut éventuellement punir. Notons tout d'abord que le caractère "vicieux" de l'enfant justifie, au moins partiellement, des "abus de correction paternelle" qui tiennent de la torture pure et simple.

"Le 21 octobre 1890, sur les onze heures du soir, la gendarmerie est informée que le né J. a attaché son enfant à un anneau sur la voie publique et qu'il l'a laissé seul. Les gendarmes qui se transportent immédiatement au lieu indiqué trouvent en effet le jeune J. attaché à un anneau scellé au mur. Une chaîne fortement serrée autour du cou obligeait l'enfant à se tenir par moments sur la pointe des pieds, parce que l'anneau était trop élevé pour sa taille. J. avait fait des menaces aux voisins et promis de se venger de la personne qui viendrait délivrer son fils; pour plus de sûreté il avait placé un cadenas à la chaîne et il fallut limer un anneau de cette chaîne pour mettre fin à cette scène scandaleuse. Pendant ce
(85) Anne-Marie

SOHN, op. cit., p. 411. 
(86) Cour de Nîmes, Tribunal d'Orange, 27/11/1890. C'est nous qui soulignons.

(87) Cour de Caen, Tribunal d'Avranches, $02 / 12 / 1891$

(88) Cour de Caen, Tribunal de Domfront, $01 / 12 / 1888$. temps, J. s'était rendu tranquillement au cabaret et il répondait au gendarme qui l'interpellait : "je vais prendre encore un verre et je viens". J. avait en partie déshabillé son fils et l'avait privé de nourriture ; l'enfant est resté dans la position qui vient d'être indiquée de 6 beures à 11 beures du soir, exposé au froid; lorsqu'il a été détivré, il était exténué de fatigue. Les renseignements recueillis ont fait connaître que J. père était adonné à la boisson et que sa conduite laissait à désirer. Toutefois la peine légère [6 jours de prison] qui a été prononcée peut s'expliquer en ajoutant que l'enfant avait de mauvais antécédents et que son caractère était des plus difficiles ". ${ }^{(86)}$

Plus même, les enfants victimes sont parfois condamnés et plus lourdement que leur(s) bourreau(x).

Pauline C., femme N., est séparée de son mari. Elle a en charge deux enfants, un fils de 7 ans et une fille de 15 ans. Elle a mauvaise réputation, "se livrant à la prostitution et vivant maritalement avec un nommé $H$. [Ce dernier] employait à la mendicité et probablement au vol les deux enfants restés à la charge de celle-ci ". Les coups pleuvent quand ils rentrent les mains vides. C. sera condamnée à 4 mois de prison et déchue de sa puissance paternelle. H. échappe à toute peine... et la jeune fille est envoyée en maison de correction jusqu'à 20 ans. ${ }^{(87)}$

Ce cas est à rapprocher de celui, jugé par le tribunal de Domfront en 1888, avant donc la loi sur la déchéance de la puissance paternelle.

Pierre L. a légitimé Jean D., âgé de 13 ans, enfant naturel de sa femme. Il l'envoie mendier et le frappe violemment si les aumônes recueillies sont insuffisantes. "Redoutant L, l'enfant préférait voler que de rentrer les mains vides à la maison. [...] L'information n'a pu établir la complicité des parents dans les divers vols commis par le jeune D., qui, acquitté comme ayant agi sans discernement, a été envoyé dans une maison de correction jusqu'à sa 20e année ". ${ }^{(8)}$

La maison de correction est-elle pour les juges un moyen de mettre le jeune Jean à l'abri? Quoi qu'il en soit, la victime est privée de liberté pour 7 ans, alors que Pierre L. purge une peine d'un mois de prison pour coups et emploi à la mendicité d'un enfant de moins de 16 ans. Il comparait à nouveau devant le tribunal en 1990. Il a récidivé avec ses propres enfants âgés de 8 et 12 ans. 


\section{CONCLUSION}

L'enquête de décembre 1891 intervient dans une période de transformation du droit de l'enfant et de la famille. La période considérée, 18871891, englobe des changements législatifs fondamentaux comme la loi de 1889 sur la déchéance de la puissance paternelle ou la loi de 1891 sur le sursis. Aux niveaux du législateur, du juge "de base", des élites locales, de la société civile nous assistons à une redéfinition de la place de l'enfant. La toute-puissance paternelle est interrogée. Dans ses souvenirs, rédigés en 1870, Norbert Truquin s'indignait de la violence de briqueteurs belges.

"Lorsque les enfants ne marchaient pas au goût du père, il tombait sur eux comme un fou furieux et les rouait de coups. Les autres ouvriers le regardaient faire sans broncher, comme si la chose était naturelle. Je me disais à part moi : il paraît qu'en Belgique on a l'babitude de traiter les enfants comme des bêtes de somme ${ }^{\left({ }^{(8)}\right.}$

En 1890, un père et son fils de quinze ans qui travaillent sur un chantier se querellent. Le père donne un coup de manche de masse à son fils qui s'enfuit. Il le poursuit et lui donne un coup de pied et quelques gifles. "Une plainte est déposée par les ouvriers du chantier contre le père " auprès de la gendarmerie. ${ }^{(90)}$ De l'indifférence à l'indignation en son for intérieur, de l'indignation à la plainte, de la plainte à l'élaboration d'une nouvelle loi, tel est le mouvement suivi en cette fin de XIXe siècle en matière de violence à enfant. Mouvement lent, non uniforme chronologiquement et géographiquement, mais qui nous conduit lentement aux numéros verts de notre fin de XXe siècle et à la lutte contre la maltraitance "grande cause nationale"...
(89) Norbert Truquin, Mémoires et aventures d'un prolétaire à travers la révolution, Paris, Maspéro, 1977, p. 44.

(90) Cour de Bourges, Tribunal de Cosnes-surLoire, 29/08/1890. 